\title{
CRESCIMENTO DO MOGNO EM SISTEMA SILVIPASTORIL
}

\author{
Micele Silva da Costa ${ }^{1}$; Clarissa Tereza Leite Feitosa ${ }^{2}$; Sanderley Simões da Cruz ${ }^{3}$; \\ Sandro Barbosa Ribeiro ${ }^{4}$; Aline Batista Fernandes Morais ${ }^{5}$; Mariana Gomes de \\ Oliveira ${ }^{6}$.
}

\footnotetext{
${ }^{1}$ Universidade Federal do Sul e Sudeste do Pará. Marabá, Pará, Brasil. micele10@ hotmail.com ${ }^{2}$ Universidade Federal do Sul e Sudeste do Pará. Marabá, Pará, Brasil. cissa_feitosa@ @otmail.com ${ }^{3}$ Instituto Federal do Pará. Marabá, Pará, Brasil. sanderley.cruz@ifpa.edu.br ${ }^{4}$ Instituto Federal do Pará.. Marabá, Pará, Brasil. sandro.barbosa@ifpa.edu.br ${ }^{5}$ Instituto Federal do Pará.. Marabá, Pará, Brasil. fernandes.aline@ifpa.edu.br

${ }^{6}$ Instituto Federal do Pará.. Marabá, Pará, Brasil. mariana.oliveira@ifpa.edu.br
}

\begin{abstract}
RESUMO: Este trabalho tem como objetivo descrever o crescimento do mogno em sistema silvipastoril. O experimento foi realizado no Campus Rural de Marabá - IFPA. Foi analisado o crescimento em altura e diâmetro altura do solo de 148 mudas de mogno no plantio e aos 2 , 4, 6, e 12 meses de idade, porcentagem de ataque pela mariposa Hypsipylla grandella Zell e porcentagem de sobrevivência das mudas em campo. $O$ delineamento utilizado foi o inteiramente casualizado, sendo que cada muda contabilizou-se como uma repetição. Os resultados da pesquisa mostram que o mogno apresentou desenvolvimento compatível com a sua idade e não foi atacado pela mariposa durante o período analisado.
\end{abstract}

PALAVRAS-CHAVE: altura, diâmetro, sobrevivência.

\section{GROWTH OF MAHOGANY IN SILVOPASTORAL SYSTEM}

\begin{abstract}
This paper aims to describe the growth of mahogany silvopastoral system. The experiment was performed at the Campus Rural Marabá - IFPA. We analyzed the growth in height and diameter ground height of 148 mahogany seedlings at planting and at 2, 4, 6, and 12 months of age, percentage of attack by moth Hypsipylla grandella Zell and survival percentage of the seedling. The experimental design was completely randomized, and each change is recorded as a repetition. The survey results show that mahogany development was compatible with his age and was not attacked by the moth during the period analyzed.
\end{abstract}

KEYWORDS: diameter, height, survival.

\section{O mogno (Swietenia macrophylla}

King) pertence à família Meliaceae, ocorre em toda a América do Sul e Central, sob os mais variados tipos climáticos. No Brasil, sua zona de ocorrência natural é a Amazônia Legal e as áreas com maior densidade de mogno encontram-se na zona de transição floresta-cerrado, no sudeste do Pará, e na porção central e norte de
Rondônia. As árvores atingem em média altura de 30 a 40 metros com até 3,5 metros de diâmetro (GROGAN et al., 2002).

Segundo Sousa et al. (1996), um dos principais motivos que desestimula o plantio comercial de mogno na Amazônia é o ataque sucessivo da mariposa Hypsipyla grandella Zell, que deposita 
seus ovos no meristema apical e suas larvas abrem galerias no caule da planta, provocando a morte do ponteiro e estimulando o superbrotamento de galhos e com isso, causam bifurcação abaixo de dois metros de altura do fuste, depreciando o valor comercial da madeira no mercado.

Os sistemas agroflorestais (SAF's) são sistemas de uso da terra e dos recursos naturais que combinam a utilização de espécies florestais, agrícolas, e, ou, criação de animais (corte, leite, equinos, ovinos e caprinos), numa mesma área, de maneira simultânea e, ou, escalonada no tempo.

Os SAF's podem contribuir para a melhoria da região, através da manutenção da biodiversidade, melhorando o status químico, físico e biológico dos solos e reduzindo a erosão, além de mudanças sociais e econômicas e o fornecimento de vários produtos e serviços ambientais (WANDELLI et al., 2004).

Neste sentido, este projeto teve como objetivo descrever o crescimento do mogno brasileiro, ocorrência do ataque da mariposa Hypsipyla grandella Zell e a taxa de sobrevivência das mudas, em sistema silvipastoril.

Este trabalho foi realizado na área do Campus Rural de Marabá (CRMB), pertencente ao Instituto Federal do Pará, no município de Marabá - Pará, com o clima classificado como Tropical Chuvoso de Selva Isotérmico (Afi), com precipitações anuais em torno de 1.925,7 $\mathrm{mm}$, e a temperatura média anual é de $28,0^{\circ} \mathrm{C}$, com máximas de $32,7{ }^{\circ} \mathrm{C}$ e mínimas de $23,3{ }^{\circ} \mathrm{C}$ (ALMEIDA, 2007).

As mudas do mogno foram produzidas a partir de sementes no viveiro do CRMB em sacos de polietileno $(17 \times 25 \mathrm{~cm}) . \mathrm{O}$ substrato utilizado foi o solo (Tabela 1) encontrado na área do Campus. Não foi realizado o manejo do solo, na área de plantio das mudas, para melhorar as suas condições físico-químicas e biológicas.

Tabela 1. Caracterização química do solo utilizado como parte do substrato no experimento.

\begin{tabular}{|c|c|c|c|c|c|c|c|c|c|c|}
\hline $\mathrm{pH}$ & $\begin{array}{c}\mathrm{P} \\
\mathrm{mg} / \mathrm{dm}^{3}\end{array}$ & $\mathrm{~K}$ & $\mathrm{Ca}$ & $\mathrm{Mg}$ & $\mathrm{Al}$ & $\begin{array}{c}\mathrm{H}+\mathrm{Al} \\
\mathrm{cmol} / \mathrm{dm}\end{array}$ & SB & CTC & $\% \mathrm{~V}$ & M.O. \\
\hline 5,9 & 53,35 & 0,38 & 2,77 & 1,01 & 0,14 & 4,90 & 4,16 & 9,06 & 45,92 & 24,31 \\
\hline
\end{tabular}


O sistema silvipastoril foi implantado em uma área de pasto de 20 ha, de capim braquiarão (Urochloa brizantha (Stapf) Webster cv. Marandu), onde foi dividido em cinco piquetes com média de quatro hectares.

As mudas levadas a campo tinham em média quatro meses de idade, sendo observado que as sementes começaram a germinar com 15 dias após a semeadura. Em seguida foram plantadas 148 mudas de mogno com espaçamento de 30 metros entre uma planta e outra, seguindo a linha da cerca externa e nas divisões dos piquetes.

O plantio das mudas na área ao redor da cerca foi realizado a distância de $1,5 \mathrm{~m}$, da mesma, já o plantio das mudas nas divisões dos piquetes foi feito também a 1,5 m da cerca, sendo plantadas dos dois lados do piquete, no mês de maio de 2012.

Foram coletados os dados de altura (distância entre o solo até a gema apical), diâmetro altura do solo (DAS), número de plantas atacadas pela Hypsipyla grandella Zell e taxa de sobrevivência de 148 plantas de mogno brasileiro (Swietenia macrophylla King.).

$\mathrm{O}$ delineamento utilizado foi $\mathrm{o}$ inteiramente casualizado, sendo que cada muda contabilizou-se como uma repetição.

A análise de avaliação do crescimento do mogno foi realizada através da medição da altura da planta e DAS no momento do plantio e aos 60, 120, 180 e 360 dias.
Para a medição de altura foi utilizada fita métrica com suas divisões em $\mathrm{cm}$ e para o DAS foi utilizado um paquímetro digital e medidas em $\mathrm{mm}$, em seguida foram transformadas para $\mathrm{cm}$.

Para diminuir os efeitos sobre o erro amostral as medições foram realizadas pela mesma pessoa em todos os períodos.

Para a determinação da taxa de sobrevivência em campo, foram contabilizadas o número de mudas plantadas com o número de mudas sobreviventes aos seis meses e um ano. Já à taxa de predação foi feita com base na observação no meristema apical de cada muda do mogno, para a visualização da broca da mariposa, com 360 dias de idade.

Os dados experimentais foram submetidos à análise de variância, através do Programa ASSISTAT versão 7.6 Beta (2011), a 5\% de significância.

As médias de altura e DAS do mogno brasileiro no plantio e aos 2, 4, 46 e 12 meses, estão apresentadas na Tabela 2. Verificou-se que as plantas apresentaram maior altura, bem como maior DAS aos 12 meses. Silva (2007) analisando o desenvolvimento do mogno solteiro (66 plantas de mogno) e consorciado (33 plantas de mogno e 33 plantas de nim; 21 plantas de mogno e 45 plantas de nim; 15 plantas de mogno e 51 plantas de nim), encontrou altura média aos 6 meses de 0,$35 ; 0,44 ; 0,48$ e $0,51 \mathrm{~m}$, respectivamente. 
Tabela 2. Crescimento em altura e diâmetro altura do solo (DAS) de 148 mudas de mogno no plantio e aos 2, 4, 6 e 12 meses e porcentagem de mortalidade aos 2, 4, 6 e 12 meses após o plantio.

\begin{tabular}{lccc}
\hline Mogno (idade) & Altura $(\mathrm{cm})$ & DAS $(\mathrm{cm})$ & \% Mortalidade \\
\hline Plantio & $37,93 \mathrm{~d}$ & $0,50 \mathrm{~d}$ & - \\
2 meses & $40,23 \mathrm{~cd}$ & $0,68 \mathrm{c}$ & 9,46 \\
4 meses & $43,81 \mathrm{bc}$ & $0,74 \mathrm{bc}$ & 11,49 \\
6 meses & $46,71 \mathrm{~b}$ & $0,78 \mathrm{~b}$ & 11,49 \\
12 meses & $69,76 \mathrm{a}$ & $1,80 \mathrm{a}$ & 47,97 \\
$\% C V$ & 25,54 & 32,58 & - \\
\hline
\end{tabular}

As médias seguidas pela mesma letra não diferem estatisticamente entre si. Foi aplicado o Teste de Tukey ao nível de $5 \%$ de probabilidade

Já para os 12 meses as médias das alturas foram de 0,$51 ; 0,77 ; 0,90$ e $0,96 \mathrm{~m}$; respectivamente. Estes dados estão próximos aos encontrados no experimento aos seis meses $(46,71 \mathrm{~cm})$ e doze meses $(69,76 \mathrm{~cm})$. Porém, os dados encontrados no trabalho são superiores aos encontrados por Souza et al (2010), que estudando as exigências nutricionais e crescimento de mudas de mogno, em quatorze tratamentos, encontrou menor e maior altura de 16,44 cm e $30,15 \mathrm{~cm}$, respectivamente.

Já para o DAS, as médias encontradas aos seis meses $(0,78 \mathrm{~cm})$ e doze meses $(1,80 \mathrm{~cm})$, estão próximos aos encontrados por Silva (2007) que comparando o diâmetro do colo do mogno em monocultivo e em consórcio com diferentes quantidades encontrou, respectivamente menor e maior DAS aos 6 meses de 0,70 e $1,10 \mathrm{~cm}$, e para os 12 meses, também respectivamente menor $(1,23 \mathrm{~cm})$ e maior $(2,30 \mathrm{~cm})$.
$\mathrm{O}$ ataque da planta do mogno pela Hypsipyla grandella Zell, ocorre principalmente na fase inicial de crescimento, tanto em condições de viveiro quanto de campo, sendo recomendado o cultivo misto com outras espécies arbóreas (SILVA, 2007). Porém, entre o período de produção das mudas até os 360 dias pósplantio não foi observado nenhum ataque desta mariposa nas plantas.

Aos 180 dias a taxa de mortalidade (tabela 2) das mudas foi de $11,49 \%$, sendo baixo mesmo se considerado que as mudas passaram por um estresse hídrico, devido elas terem sido plantadas no final do período chuvoso (maio). Porém aos 360 dias a taxa de mortalidade foi de $47,97 \%$. Dados estes próximos aos encontrados por Oliveira et al. (2009), que estudando o crescimento de espécies arbóreas nativas em sistema silvipastoril, que foi de $44 \%$ com 1 ano de idade.

Conclui-se que o mogno pode ser usado para a implantação de sistemas 
silvipastoris, apresentando um bom desenvolvimento na região sudeste do Pará.

\section{REFERÊNCIAS}

ALMEIDA, M. F. Caracterização agrometeorológica do município de Marabá - PA. 2007. 77 f. Monografia Trabalho de Conclusão de Curso (Graduação em Agronomia) Universidade Federal do Pará, Marabá, 2007.

GROGAN, J; BARRETO, P; VERISSIMO, A. Mogno na Amazônia brasileira: ecologia e perspectivas Manejo. Belém: Imazon, 2002. 56p.

OLIVEIRA, T.K; LUZ, S.A; SANTOS, F.C.B; OLIVEIRA, T.C; LESSA, L.S. Crescimento de espécies arbóreas nativas em sistema silvipastoril no Acre. Amazônia: Ciência \& Desenvolvimento. Belém. v.4, n.8, jan/jun, p. 9-32, 2009.

SILVA, M. C. A. Influência do arranjo espacial do mogno (Swietenia macrophylla king) com o nim (Azadirachta indica A. Juss) como barreira natural ao ataque da Hypsipyla grandella Zeller. Belém, 2007. 72 f. Dissertação (Mestrado em Ciências Florestais) - Universidade Federal Rural da Amazônia, Belém, 2007.

SILVA, F. A. S. ASSISTAT Versão 7.6 Beta (2011). Disponível em: <http://www.assistat.com/indexp.html\#ref >. Acesso em: 12 de dez. 2012.

SOUSA, S.G.A; MATOS, J.C; ARCOVERDE, M; WANDELLI, E; PERIN, R; FERNANDES, E. Comportamento do mogno (Swietenia macrophylla King) em sistemas agroflorestais na Amazônia Ocidental,
1996. In: SIMPÓSIO INTERNACIONAL SOBRE ECOSSISTEMAS FLORESTAIS, 4. : 1996 : Belo Horizonte. Anais... Belo Horizonte: Biosfera, 1996. CD-ROM.

SOUZA, C. A. S; TUCCI, C. A. F; SILVA, J. F; RIBEIRO, W. O. Exigências nutricionais e crescimento de plantas de mogno (Swietenia macrophylla King.). ACTA AMAZÔNICA. vol 40. p.515 $522,2010$.

WANDELLI, E. V.; FERNANDES, E. SOUSA, S. G. S.; PERIN, R.; COSTA, J. R. Serviços ambientais e produtos de sistemas agroflorestais e da vegetação secundária no processo de recuperação de áreas degradadas na Amazônia Central, 2004. In: CONGRESSO BRASILEIRO DE SISTEMAS AGROFLORESTAIS, 5. Curitiba. SAFs: desenvolvimento com proteção ambiental: Anais... Colombo: Embrapa Florestas, 2004. p.172-174. (Embrapa Florestas. Documentos, 98). 